\title{
A AÇÃO DIRETA DE \\ INCONSTITUCIONALIDADE DE NORMA MUNICIPAL EM FACE DA LEI ORGÂNICA DO MUNICÍPIO
}

THE DIRECT ACTION OF UNCONSTITUTIONALITY OF MUNICIPAL LAW OVER THE ORGANIC LAW OF THE MUNICIPALITY

LA ACCIÓN DIRECTA DE LA INCONSTITUCIONALIDAD DE LA NORMA MUNICIPAL FRENTE A LA LEY ORGÁNICA DEL MUNICIPIO

Mário Sérgio Falcão Maia ${ }^{1}$

Rodrigo de Almeida Leite ${ }^{2}$

1 Mestre em Direito pela Universidade Federal da Paraíba (UFPB) e Doutor em Direito pela Universidade Federal de Pernambuco (UFPE). Professor do Curso de Direito da Universidade Federal Rural do Semiárido (UFERSA). E-mail: mmaia22@yahoo.com.

2 Especialista em Direito e Políticas da União Europeia pela Universidade de Salamanca. Mestre em Direito pela Universidade Clássica de Lisboa e Doutorando em Ciência Política pela Universidade Federal de Pernambuco (UFPE). Professor do Curso de Direito da Universidade Federal Rural do Semiárido (UFERSA). Membro do Grupo de Pesquisa em Direito Administrativo e Constitucional (GPDAC-UFERSA).E-mail: rodrigoleite@ufersa.edu.br. 
Resumo: O presente ensaio vista tecer argumentos sobre um tipo de controle de normas que é pouco referenciado pela doutrina: a possibilidade do controle concentrado de normas municipais em face de Lei Orgânica Municipal, sendo mais especificadamente a utilização de Ação Direta de Inconstitucionalidade destas normas perante os Tribunais de Justiças Estaduais. Neste sentido, procurou-se demonstrar quais são os argumentos contrários a este tipo de controle expostos pela doutrina e jurisprudência e, por meio do método indutivo, da análise legislativa e da revisão bibliográfica, partiu-se para a construção de fundamentos em sentido oposto, de forma a tornar plenamente possível esta análise sui generis de constitucionalidade de normas municipais, sem perder de vista as dificuldades inerentes ao seu reconhecimento, que são a inexistência de previsão expressa na Constituição Federal, a consideração da Lei Orgânica Municipal como uma norma de direito comum (resultando assim em um conflito de legalidade) e a ausência de um Poder Judiciário Municipal para julgar esta ação, nos mesmos moldes do que ocorre com o controle abstrato de constitucionalidade no âmbito federal e estadual.

Palavras-Chave: Controle de Constitucionalidade. Norma Municipal. Lei Orgânica.

Abstract: This essay offers some arguments on a type of control of law that is little referenced by the doctrine: the possibility of concentrated control of municipal norms in the face of Organic Municipal Law, more specifically, the use of direct action of unconstitutionality of these norms before the State Courts of Justices. We therefore sought to demonstrate the arguments that exist against this type of control exhibited by the doctrine and jurisprudence, and through the inductive method, analysis of the legislation, and a literature review, to build the foundations in the opposite direction, seeking to enable this sui generis analysis of constitutional standards of municipal laws, without losing sight of the inherent difficulties to their recognition, namely, the absence of express provision in the Federal Constitution, the perception of Municipal Organic Law as a rule of common law (resulting in a 
conflict of legality) and the absence of a Municipal Court of Justice to prosecute this action, along the lines of what happens with the abstract control of constitutionality at federal and state levels.

Key-Words: Control of Constitutionality. Municipal Law. Organic Law.

Resumen: El presente ensayo pretende esbozar argumentos acerca de un tipo de control de normas que es poco referenciado por la doctrina: la posibilidad del control concentrado de normas municipales a la luz de la Ley Orgánica Municipal, más específicamente la utilización de la Acción Directa de Inconstitucionalidad de estas normas ante los Tribunales de Justicia Estaduales. En este sentido, se intentó demostrar cuáles son los argumentos contrarios a este tipo de control expuestos por la doctrina y jurisprudencia. Por medio del método inductivo, del análisis legislativo y de la revisión bibliográfica, se dio partida hacia la construcción de fundamentos en un sentido opuesto, para hacer plenamente posible este análisis sui generis de constitucionalidad de normas municipales sin perder de vista las dificultades inherentes a su reconocimiento, que son la no existencia de previsión expresa en la Constitución Federal, la consideración de la Ley Orgánica Municipal como una norma de derecho común (resultando así en un conflicto de legalidad) y la ausencia de un Poder Judicial Municipal para juzgar esta acción, en los mismos moldes de lo que ocurre con el control abstracto de constitucionalidad en el ámbito federal y estadual.

Palabras Clave: Control de Constitucionalidad. Norma Municipal. Ley Orgánica.

INTRODUÇÃO

tema que ora se enfrenta é por demais desafiador. Existe por trás de sua discussão um desejo de justiça e a esperança de uma evolução no sistema de controle de constitucionalidade no ordenamento 
jurídico brasileiro. Deve-se advertir também que são poucas as referências nos diversos manuais de Direito Constitucional, além de que em obras específicas, os autores costumam posicionar-se em sentido contrário à tese ora defendida.

O Município foi regulamentado na Constituição Federal de 1988 de forma peculiar: afastou-se da fórmula tradicional do Federalismo, trazendo um ar inovador. Este ente passou então a fazer parte oficial da estrutura políticoadministrativa da federação, que deixou de ser binária (Estados e União) para incluir também o Município nesta tríade federativa.

Nesta nova arquitetura, a Constituição Federal designou competências específicas para o Município, além de competências concorrentes com os demais entes. Determinou também que ele seja regido por uma norma especial, consubstanciada na Lei Orgânica Municipal, que deverá ser elaborada não pelos Estados, mas sim pela Câmara de Vereadores, disciplinando as matérias atribuídas pela Carta Magna.

O Município assim passa a ter as mesmas características que os Estados: ele se autogoverna, autoadministra e se auto-organiza, por meio de seu poder de normatização próprio (modificação de sua norma fundamental - Lei Orgânica e por meio de suas normas municipais). Contudo, a doutrina e a jurisprudência ainda são reticentes em reconhecer o parâmetro de constitucionalidade formal das leis orgânicas municipais.

Além deste fato, a norma municipal talvez seja a que mais careça de instrumentos para auferir a sua constitucionalidade de forma abstrata: a única possibilidade (expressa) $)^{3}$ se dá com a representação de lei municipal ante a Constituição do Estado. O Supremo Tribunal Federal já pacificou que não pode haver controle de constitucionalidade concentrado de norma municipal em face da Constituição Federal (em nenhum Tribunal, a não ser de modo difuso), além de haver também um precedente específico isolado do STF e raros pronunciamentos doutrinários sobre o controle concreto de norma municipal em razão de sua Lei Orgânica.

3 Não se pode deixar de mencionar que existe a possibilidade de se utilizar a Arguição de Descumprimento de Preceito Fundamental (ADPF) perante o STF, para questionar a constitucionalidade de norma municipal em razão da Constituição Federal. Contudo, esta ação possui um filtro bastante criterioso, conforme será visto em seguida, o que em muitos casos impede o uso deste tipo de ação. 
É neste sentido que se procura abordar este tema ainda nebuloso na doutrina e na jurisprudência dos tribunais. Desta forma, será discutido sobre de que modo pode vir a existir um controle concentrado de normas municipais em face da respectiva Lei Orgânica, para tanto, o foco estará na possibilidade da utilização da Ação Direta de Inconstitucionalidade - por ser o instrumento básico deste tipo de controle - a ser ajuizada perante os Tribunais de Justiça do Estado.

Neste trabalho realizou-se pesquisa bibliográfica e jurisprudencial, além de análise dogmática sobre o tema, dividindo-se sua estrutura em três partes: a apresentação da forma como hoje se realiza o controle de constitucionalidade de normas municipais, as objeções à possibilidade da utilização da Ação Direta de Inconstitucionalidade de leis municipais em face da Lei Orgânica e, por fim, os fundamentos a favor deste tipo de controle de constitucionalidade peculiar.

O CONTROLE DE CONSTITUCIONALIDADE DE NORMAS MUNICIPAIS: POSSIBILIDADES

O controle abstrato de constitucionalidade das normas municipais talvez seja um dos tipos de controle que mais padeça de "lacunas". Isto porque em tese é permitida a sua análise de forma ampla no caso concreto (controle difuso), por qualquer magistrado, sendo restrita a análise de constitucionalidade de forma genérica (concentrada).

A utilização de Ação Direta de Inconstitucionalidade (ADIN) de normas municipais está bem pacificada na doutrina e na jurisprudência, além de haver previsão expressa na Constituição Federal (CF). É praticamente unânime o posicionamento de que o único controle de constitucionalidade de normas municipais se dá em relação às Constituições Estaduais. Aliás, este é o enunciado do art. 125, § $2^{\circ}$, da CF, que determina que "cabe aos Estados a instituição de representação de inconstitucionalidade de leis ou atos normativos estaduais ou municipais em face da Constituição Estadual".

Desta forma, havendo uma violação de uma norma municipal à Constituição Estadual, a respectiva ADIN deve ser impetrada perante o Tribunal de Justiça 
local, de acordo com as disposições da Constituição Estadual e do Regimento Interno do Tribunal.

Por outro lado, entende-se não haver a possibilidade de ação direta de inconstitucionalidade de leis municipais em face da Constituição Federal. E a razão deste fato se dá justamente na ausência de disposição expressa na Constituição para este tipo de controle 4 , que somente permite ADIN perante o Supremo Tribunal Federal (STF) de lei ou ato normativo federal ou estadual em relação à Carta Magna 5 .

De acordo com o posicionamento de Uadi Bulos, o que se deu neste caso não foi uma lacuna do constituinte, mas sim uma atitude proposital. Segundo o jurista, o sentido desta ausência de regulamentação foi evitar uma avalanche de ações questionando leis municipais no STF, tendo como base a Constituição Federal. Assim, a medida passou a ter um caráter mais prático do que justo ${ }^{6}$.

O resultado das afirmações anteriores é que o "mais comum" é que possa haver controle de constitucionalidade de lei municipal em face da Constitucional Federal no caso concreto, ou seja, realizado por cada juiz, tendo a decisão efeito inter partes. Uma possibilidade de controle concentrado destas normas seria com o uso da Arguição de Descumprimento de Preceito Fundamental (ADPF), que inclui, entre o rol de normas objetos desta ação, a lei municipal em contraste com a Constituição Federal. Contudo, a ADPF tem caráter supletivo, além de seus requisitos próprios que em muitos casos inviabilizam o uso da ação, a exemplo da discussão sobre o que é preceito fundamental ${ }^{7}$, o que inviabilizaria a verificação de constitucionalidade da norma municipal com uma norma de direito material da Constituição Federal que não fosse considerada um preceito.

4 Lenio Streck denomina esta ausência de "silêncio eloquente". Cfr. STRECK, Lenio Luiz. Jurisdição Constitucional e Decisão Jurídica. 4. ed. São Paulo: Revista dos Tribunais, 2014, p. 80.

5 Vid. BRASIL. Constituição Federal. Art. 102, I, alínea "a".

6 BULOS, Uadi Lammêgo. Curso de Direito Constitucional. 6. ed. São Paulo: Saraiva, 2011, p. 204.

7 Sobre a discussão, vid. o comentário de Lenio Streck: "Além de tudo isso, persiste outra adversidade, consistente na dificuldade de estipular o que é princípio e o que é preceito. Mais ainda, não se pode olvidar a necessária diferenciação entre preceitos constitucionais e preceitos fundamentais, conceito que exsurge, por exemplo, do próprio instituto da arguição de descumprimento de preceito fundamental (ADPF). Nesse caso, parece razoável afirmar que preceitos fundamentais são todos aqueles que dizem respeito aos direitos fundamentais, razão do próprio Estado Democrático de Direito. Todos os direitos fundamentais podem ser considerados preceitos fundamentais; entretanto, nem todos os preceitos fundamentais são enquadráveis no catálogo dos direitos fundamentais". STRECK, Lenio Luiz. Jurisdição Constitucional e Decisão Jurídica, p. 856. 
A jurisprudência do STF, contudo, chega a permitir que, caso uma lei municipal venha a violar além de uma norma da Constituição Federal, também um dispositivo expresso da Constituição Estadual, mesmo que seja de repetição obrigatória e redação idêntica, a ADIN poderá ser impetrada perante o Tribunal de Justiça do Estado $^{8}$ nos termos do já referido art. 125, § 2² da Constituição Federal. Porém, a orientação do Supremo Tribunal é que, no momento em que os Tribunais de Justiça dos Estados realizem este tipo de controle concentrado, somente podem utilizar a Constituição do Estado como parâmetro verificador, sendo proibido, em sede de ADIN (no Tribunal de Justiça Estadual), analisar leis ou atos normativos municipais em face da Constituição Federal ${ }^{9}$.

Sobre este último ponto, a doutrina identifica que, caso houvesse uma decisão com efeitos erga omnes do Tribunal de Justiça Estadual - realizando controle de constitucionalidade abstrato, tendo como parâmetro a Constituição Federal -, tal decisão estadual iria vincular o STF, o que não seria permitido. Se assim ocorresse, o órgão judicial estadual estaria interpretando a Constituição Federal em controle concentrado, vinculando o Supremo à jurisdição estadual, e sobrepondo-se ao mister de guarda da Constituição que foi designado ao nosso Tribunal Constitucional ${ }^{10}$.

Por fim, há outra possibilidade de controle de constitucionalidade de leis municipais que praticamente não é citada por parte da doutrina. É o controle concentrado de lei municipal em face da Lei Orgânica do Município, mais especificadamente por meio de uma Ação Direta de Inconstitucionalidade.

Poucos autores têm se pronunciado sobre este tema, e mesmo aqueles que abordam o controle abstrato de constitucionalidade de leis municipais,

8 Gilmar Mendes ressalta que o Supremo Tribunal Federal jurisprudencialmente pacificou que, caso haja a propositura de uma ADIN perante o STF e outra sobre o Tribunal de Justiça Estadual, "com base em direito constitucional federal de reprodução obrigatória pelos Estados-membros, há de se suspender o processo no âmbito da Justiça estadual até a deliberação definitiva da Suprema Corte. O Tribunal acabou, portanto, por consagrar uma causa especial de suspensão do processo no âmbito da Justiça Local, nos casos de tramitação paralela de ações diretas perante o Tribunal de Justiça e perante a própria Corte relativamente ao mesmo objeto, e com fundamento em norma constitucional de reprodução obrigatória por parte do Estado-membro". MENDES, Gilmar Ferreira; GONET BRANCO, Paulo Gustavo. Curso de Direito Constitucional. 9. ed. São Paulo: Saraiva, 2014, p.1.153.

9 BRASIL. SUPREMO TRIBUNAL FEDERAL. ARE 645992 AgR / GO, Segunda Turma, Relator: Min. Ricardo Lewandowski. Julgamento: 26/06/2012.

10 Neste sentido, vid. MORAES, Alexandre de. Direito Constitucional. 29. ed. São Paulo: Atlas, 2013, p. 752-753. 
poucas linhas dedicam ao enfrentamento da lei municipal ante a Lei Orgânica Municipal.

O objetivo deste artigo é justamente discutir esta possibilidade de controle de constitucionalidade, cuja hipótese nasceu de uma pesquisa para um caso concreto envolvendo uma lei do Município de Recife, no Estado de Pernambuco, que talvez tenha sido o único Estado do país que trouxe originalmente em sua Constituição esta previsão.

Conforme será visto, o Tribunal de Justiça de Pernambuco retrocedeu neste âmbito, declarando em sede de ADIN que a disposição da Constituição de Pernambuco que permitia este tipo de controle era inconstitucional. Considerase que esta seria uma ótima oportunidade para haver uma evolução no controle de constitucionalidade no Brasil, mas que não logrou êxito.

É neste sentido que serão discutidas agora as objeções ao controle concentrado de constitucionalidade de leis municipais em face das leis orgânicas, além das razões pelas quais se defende que este tipo de controle é possível no ordenamento jurídico brasileiro.

\section{OBJEÇÕES À POSSIBILIDADE DA UTILIZAÇÃO DE AÇÃO DIRETA DE INCONSTITUCIONALIDADE DE NORMA MUNICIPAL EM FACE DE LEI ORGÂNICA}

Para a discussão deste tópico, toma-se como base a ADIN n. 140965-011, impetrada e julgada no Tribunal de Justiça de Pernambuco (TJPE), além dos poucos pronunciamentos doutrinários sobre esse tema por demais específico.

O Estado de Pernambuco talvez tenha sido o único no país a prever originalmente em sua Constituição a possibilidade do ingresso de ADIN de lei municipal em face da respectiva Lei Orgânica Municipal ${ }^{12}$, sendo seguido também pelo Regimento Interno do TJPE.

11 BRASIL. TRIBUNAL DE JUSTIÇA DE PERNAMBUCO. ADIN n. 140965-0, Corte Especial, Relator: Des. Bartolomeu Bueno, Julgamento: 12/06/2008.

12 TAVARES, André Ramos. Curso de Direito Constitucional. 10. ed. São Paulo: Saraiva, 2012, p. 482483. 
Neste sentido, a Constituição do Estado assim se pronunciava sobre este controle:

Art. 61. Compete ao Tribunal de Justiça:

I - processar e julgar originariamente:

I) a ação direta de inconstitucionalidade de lei ou ato normativo estadual ou municipal, em face desta Constituição, ou de lei ou ato normativo municipal em face da Lei Orgânica respectiva;

O Regimento Interno do Tribunal de Justiça de Pernambuco também seguiu a mesma fórmula e designava que:

Art. 22 - Compete à Corte Especial:

I - Processar e julgar, originariamente:

$[\ldots]$

h) a ação direta de inconstitucionalidade de lei ou ato normativo estadual em face da Constituição ou de lei ou ato normativo municipal em face da Lei Orgânica respectiva;

Para discutir este capítulo, cita-se aqui também a ementa da decisão que declarou inconstitucional a possibilidade do uso de ADIN em Pernambuco para realizar o controle concentrado de lei municipal em face de Lei Orgânica, para que a mesma facilite o entendimento da matéria e sirva para a análise dos tópicos que serão desenvolvidos em seguida.

EMENTA: CONSTITUCIONAL - AÇÃO DIRETA DE INCONSTITUCIONALIDADE DE LEI MUNICIPAL EM FACE DE LEI ORGÂNICA MUNICIPAL - PRELIMINAR DE IMPOSSIBILIDADE JURÍDICA DO PEDIDO ACOLHIDA UNANIMAMENTE - DECLARAÇÃO INCIDENTAL DE INCONSTITUCIONALIDADE PARCIAL DO ARTIGO 61, INCISO I, ALÍNEA "L" DA CONSTITUIÇÃO ESTADUAL E DO ARTIGO 22, INCISO 
I, ALÍNEA "H" DO REGIMENTO INTERNO DO TJPE, COM REDUÇÃO DO TEXTO, PARA EXCLUIR A PARTE QUE PERMITE O AJUIZAMENTO DE AÇÃO DIRETA DE INCONSTITUCIONALIDADE DE LEI OU ATO NORMATIVO MUNICIPAL EM FACE DE LEI ORGÂNICA MUNICIPAL EXTINÇÃO DO FEITO SEM RESOLUÇÃO DO MÉRITO.

1. Preliminar de impossibilidade jurídica do pedido suscitada pela Procuradoria de Justiça: é forçoso, dado a jocosidade dos argumentos colacionados na doutrina e na jurisprudência pátrias, acolher o entendimento segundo o qual a Constituição Federal vigente veda o uso de ADIN para contrastar lei municipal em face de Lei Orgânica local. Aliás, tal possibilidade é vedada ao Supremo Tribunal Federal, ainda que o controle concentrado de lei ou ato normativo municipal seja pleiteado em razão da Constituição Republicana.

2. Com efeito, descabe discutir em ação direta de inconstitucionalidade violação de normas da Carta Magna por leis ou atos normativos municipais. São palavras de Luis Roberto Barroso: 'do texto expresso do art. 102, I, a, extrai-se que a ação direta de inconstitucionalidade terá por objeto somente lei ou ato normativo federal ou estadual, com exclusão deliberada de normas municipais. Por tal razão a Jurisprudência do Supremo Tribunal Federal reiteradamente se pronunciou no sentido do descabimento do controle por ação direta de inconstitucionalidade de lei ou ato normativo municipal em face da Constituição Federal e, mais ainda, veda que a Constituição do Estado atribua ao Tribunal de Justiça competência para processar e julgar representação de inconstitucionalidade de lei ou ato normativo municipal em face da Constituição Federal, em usurpação de competência do Supremo Tribunal Federal' (in: O Controle de Constitucionalidade no Direito Brasileiro. São Paulo: Saraiva, 2004, p. 138)".

3. Invoque-se a decisão do Pretório Excelso na Reclamação n. 595-SE, Tribunal Pleno, rel. Min. Sidney Sanches, j. 28.08.2002, p. 23.05.2003.

4. Da mesma forma, não se admite discutir em ADIn eventual infringência a norma infraconstitucional, no caso, ao artigo 40 e 41 da respectiva Lei Orgânica Municipal. Quando se está diante de questão de legalidade, descabe a ação direta (cf. v.g., ADIn 2.387-DF, rel. orig. Min. Marco Aurélio, rela. para ac. Min. Ellen Gracie, 21.02.2001). E nunca será demasiado lembrar do que dispõe o art. $125, \S 2{ }^{\circ}$., da Constituição da República (com grifos acrescidos): 'Cabe aos Estados a Instituição de representação de inconstitucionalidade de leis ou atos normativos estaduais ou municipais em face da Constituição Estadual, vedada a 
atribuição da legitimação para agir a um único órgão'".

5. Preliminar acolhida unanimemente para: a) declarar incidentalmente, e com redução de texto, a inconstitucionalidade parcial do artigo 61 , inciso I, alínea "I" da Constituição do Estado de Pernambuco e do artigo 22, I, " $h$ ", do Regimento Interno do Tribunal de Justiça de Pernambuco, conferindo a estes dispositivos legais a interpretação conforma a Constituição do Estado de Pernambuco, para excluir a parte dos textos que permitem o ajuizamento de ação direta de inconstitucionalidade de lei ou ato normativo municipal em face da Lei Orgânica Municipal; b) extinguir o processo sem resolução do mérito, a teor do artigo $3^{\circ}$., inciso I, da Lei n. 9.868/99 e artigo 267, inciso IV, do Código de Processo Civil $^{13}$.

Ao analisar os fundamentos contrários a este tipo de controle, observa-se que três questões são levantadas: a) a ausência de previsão expressa na Constituição Federal para este tipo de controle; b) a afirmativa que as leis orgânicas dos municípios não são consideradas "constituições" dos Municípios, e assim se trata de um exame de legalidade; c) não há um tribunal ou juiz municipal designado para julgar a "inconstitucionalidade" de uma lei municipal frente à Lei Orgânica deste ente federal.

Apenas a título de informação, curiosamente, a Constituição do Estado de Pernambuco disponível no website do Governo do Estado e da Assembleia Legislativa não está atualizada e ainda consta com a redação original do dispositivo. Assim também se encontra a Constituição Estadual no site do Tribunal de Justiça de Pernambuco (TJPE). Frise-se que o único texto normativo que faz menção a esta modificação está no Regimento Interno do TJPE, disponibilizado em seu website ${ }^{14}$.

Esta ausência de informação atualizada acaba por prejudicar os profissionais da área jurídica que laboram no Estado de Pernambuco, tendo em vista que a Constituição Estatal disponibilizada nos sites oficiais dos Poderes do Estado encontra-se desatualizada. Ademais, acaba também por gerar informação errada para a doutrina que trabalha com o tema, levando a tirar conclusões inverídicas para com a realidade.

13 BRASIL. TRIBUNAL DE JUSTIÇA DE PERNAMBUCO. ADIN n. 140965-0, Corte Especial, Relator: Des. Bartolomeu Bueno, Julgamento: 12/06/2008.

14 Dados verificados em 09 de fevereiro de 2015. 


\section{AUSÊNCIA DE PREVISÃO EXPRESSA NA CONSTITUIÇÃO \\ FEDERAL}

Parte da fundamentação do Tribunal de Justiça do Estado de Pernambuco baseou-se najustificativa de que o Supremo Tribunal Federal não tem competência para analisar ADIN de lei municipal em face da Constituição Federal, além do fato de não existir previsão expressa na Constituição Federal para a representação de inconstitucionalidade de lei municipal em face da respectiva Lei Orgânica na Justiça Estadual, abstraindo-se tais lições dos seguintes dispositivos constitucionais:

Art. 102. Compete ao Supremo Tribunal Federal, precipuamente, a guarda da Constituição, cabendo-Ihe:

I - processar e julgar, originariamente:

a) a ação direta de inconstitucionalidade de lei ou ato normativo federal ou estadual e a ação declaratória de constitucionalidade de lei ou ato normativo federal;

Art. 125. Os Estados organizarão sua Justiça, observados os princípios estabelecidos nesta Constituição.

\section{$[\ldots]$}

$\S 2^{\circ}$ - Cabe aos Estados a instituição de representação de inconstitucionalidade de leis ou atos normativos estaduais ou municipais em face da Constituição Estadual, vedada a atribuição da legitimação para agir a um único órgão.

Ademais, estranhamente o TJPE "invoca" uma jurisprudência que assentou bases no STF, relativamente à impossibilidade dos tribunais de justiça estaduais julgarem ADIN's de lei municipais em face da Constituição Federal: 
EMENTA: - DIREITO CONSTITUCIONAL E PROCESSUAL CIVIL. AÇÃO DIRETA DE INCONSTITUCIONALIDADE DE LEI MUNICIPAL, EM CURSO NO TRIBUNAL DE JUSTIÇA DE SERGIPE, COM LIMINAR DEFERIDA. RECLAMAÇÃO PARA O SUPREMO TRIBUNAL FEDERAL. PROCEDÊNCIA. 1. Dispõe o art. 106, I, "C", da Constituição do Estado de Sergipe: "Art. 106. compete, ainda, ao Tribunal de Justiça: I - processar e julgar originariamente: ... "c" - a ação direta de inconstitucionalidade de lei ou atos normativos estaduais em face da Constituição Estadual e de lei ou de ato normativo municipal em face da Constituição Federal ou da Estadual". 2. Com base nessa norma, o Tribunal de Justiça do Estado de Sergipe tem julgado Ações Diretas de Inconstitucionalidade de leis municipais, mesmo em face da Constituição Federal. 3. Sucede que esta Corte, a 13 de março de 2002, tratando de norma constitucional semelhante do Estado do Rio Grande do Sul, no julgamento da ADI no 409, Relator Ministro SEPÚLVEDA PERTENCE (DJ de 26.04.2002, Ementário n० 2066-1), decidiu: "Controle abstrato de constitucionalidade de leis locais (CF, art. $\left.125, \S 2^{\circ}\right)$ : cabimento restrito à fiscalização da validade de leis ou atos normativos locais - sejam estaduais ou municipais -, em face da Constituição estadual: invalidade da disposição constitucional estadual que outorga competência ao respectivo Tribunal de Justiça para processar e julgar ação direta de inconstitucionalidade de normas municipais em face também da Constituição Federal: precedentes". 4. Adotados os fundamentos apresentados nesse aresto unânime do Plenário e em cada um dos precedentes neles referidos, a presente reclamação é julgada procedente, para se extinguir, sem exame do mérito, o processo da Ação Direta de Inconstitucionalidade $n^{\circ}$ 02/96, proposta perante o Tribunal de Justiça do Estado Sergipe, por falta de possibilidade jurídica do pedido, cassada definitivamente a medida liminar nele concedida. 5. Incidentalmente, o S.T.F. declara a inconstitucionalidade das expressões "Federal ou da", constantes da alínea "c" do inciso I do art. 106 da Constituição do Estado de Sergipe. 6. A esse respeito, será feita comunicação ao Senado Federal, para os fins do art. 52, X, da Constituição Federal. E também ao Tribunal de Justiça de Sergipe ${ }^{15}$.

Não obstante as diretrizes anteriormente referidas serem válidas em seus devidos campos, elas não se aplicam ao caso em concreto. Isto porque não se quer que o Tribunal de Justiça Estadual examine a constitucionalidade de lei municipal em face da Constituição Federal, tampouco se pede que o STF verifique a compatibilidade de lei municipal ante a Carta Magna.

A questão em análise é distinta: refere-se à possibilidade da utilização de ADIN perante o Tribunal de Justiça Estadual para verificar a compatibilidade de 15 BRASIL. SUPREMO TRIBUNAL FEDERAL. Rcl 595/SE, Relator: Min. Sydney Sanches, Julgamento: 28/08/2002. 
lei municipal em razão de Lei Orgânica Municipal.

Neste ponto a jurisprudência do STF é antiga e escassa e não expõe com maiores detalhes a razão de não existir o tipo de controle ora almejado, apenas informa que não existe previsão constitucional:

EMENTA: Recurso Extraordinário. 2. Controle concentrado de constitucionalidade de li municipal em face da Lei Orgânica do Município. Inexistência de previsão constitucional. 3. Recurso não conhecido.

Voto do Min. Néri da Silveira (Relator):

Não conheço do recurso extraordinário. No AgRg na ADIN 1268 (DJ de 20.10.95), relator o Senhor Ministro Carlos Velloso, o Plenário assentou:

'EMENTA: CONSTITUCIONAL. LEI OU ATO NORMATIVO MUNICIPAL FRENTE À CONSTITUIÇÃO FEDERAL: CONTROLE CONCENTRADO. INEXISTÊNCIA. I. - Inexiste controle concentrado de lei ou ato normativo municipal frente a Constituição Federal, quer perante os Tribunais de Justiça dos Estados, quer perante o Supremo Tribunal Federal (C.F., art. 102, I, "a"; art. 125, PAR. 2.).

A Constituição Federal somente admite o controle, em abstrato, de lei ou ato normativo municipal em face da Constituição Estadual, junto ao Tribunal de Justiça do Estado (C.F., art. 125, PAR. 2).

Ora, no caso concreto, o acórdão recorrido registrou tratar-se de controle concentrado de lei municipal em face da Lei Orgânica do mesmo município, o que não possui previsão constitucional. [...] $]^{16}$.

Data Venia o posicionamento do Supremo Tribunal Federal nesta matéria, considera-se que esta exegese automática deve ser modificada para adequarse aos princípios constitucionais aplicados à jurisdição constitucional que foram sendo modificados ao logo do tempo. No capítulo 3 serão tratadas com maiores detalhes as razões de entender-se que não existe proibição para este controle

16 BRASIL. SUPREMO TRIBUNAL FEDERAL. Recurso Extraordinário n. 175.087-1 - SP, $2^{\mathrm{a}}$. Turma, Rel.: Min. Néri da Silveira, Julgamento: 19/03/2002. 
abstrato de constitucionalidade de lei municipal em razão de Lei Orgânica, desde que previsto expressamente na Constituição do respectivo Estado.

\section{CONSIDERAÇÃO DA LEI ORGÂNICA COMO UMA LEI "COMUM"}

Quando se trata de controle de constitucionalidade, tanto a jurisprudência do TJPE como a doutrina é pacífica em afirmar ser impossível o controle de leis municipais, tendo como parâmetro a Lei Orgânica do Município, pelo fato de ela ser uma lei infraconstitucional, sem o caráter de constitucionalidade.

Em obra específica sobre o controle de constitucionalidade de leis municipais, Celio Janczeski também se posiciona neste sentido:

Naquelas hipóteses em que a Lei Orgânica for afrontada por lei ou ato normativo municipal haverá ilegalidade, por desrespeito da norma de hierarquia superior, a ser solvida com a aplicação de todas as regras e recursos previstos para os processos em geral.

\section{$[\ldots]$}

Apesar de se entender a Lei Orgânica como a Constituição do Município, formalmente ela não se trata de uma Constituição. Eventual incompatibilidade entre a lei municipal com a Lei Orgânica resolve-se no campo do direito infraconstitucional ${ }^{17}$.

Resulta desta assertiva que grande parte da doutrina entende que a Lei Orgânica, apesar de ser uma norma de caráter organizacional, é uma norma de direito comum ${ }^{18}$, o que impediria o controle abstrato de constitucionalidade de leis municipais, tendo-a como referência.

17 JANCZESKI, Célio Armando. O Controle de Constitucionalidade de Leis Municipais. Florianópolis: Conceito Editorial, 2009, p. 231.

18 TAVARES, André Ramos. Curso de Direito Constitucional, p. 482. 


\section{INEXISTÊNCIA DE UM “PODER JUDICIÁRIO MUNICIPAL" PARA JULGAR A (IN)CONSTITUCIONALIDADE DE UMA LEI MUNICIPAL EM FACE DA LEI ORGÂNICA}

Realizar um controle de constitucionalidade de lei municipal em face de uma Lei Orgânica suscita questionamentos interessantes, porque qualquer tentativa de previsão deste modelo fará copiar a mesma estrutura existente em nível federal e estadual: o Supremo Tribunal Federal analisa a constitucionalidade de lei ou ato normativo estadual ou federal em relação à Constituição Federal, enquanto que os Tribunais de Justiça Estaduais podem analisar a constitucionalidade de leis ou atos normativos municipais e estaduais, tendo como parâmetro a Constituição Estadual.

Logo, em um "juízo lógico superficial", o controle concentrado de leis municipais em face das leis orgânicas deveria ser de competência de uma suposta "justiça municipal".

Este detalhe foi também suscitado por André Tavares, que acertadamente pondera:

Inexistindo, porém, nos Municípios, um Judiciário próprio, não se poderia cogitar da atribuição de competência a qualquer órgão municipal para exercer tal controle. Além disso, é vedado constitucionalmente aos Municípios instituir normas de Direito Processual, o que os impede de criar mecanismos de controle jurisdicional concentrado de suas normas ${ }^{19}$.

Sem embargo, conforme será demonstrado mais adiante, nada impede que ante o caráter sui generis deste tipo de controle ele seja efetuado pelo Tribunal de Justiça Estadual, sendo regulamentado pela Constituição do Estado, posto que a própria Constituição Federal permite que os Estados legislem em matéria processual e que o Estado defina as competências de seu Tribunal ${ }^{20}$. 


\section{A TESE A FAVOR DO CONTROLE ABSTRATO DE LEI MUNICIPAL EM FACE DE LEI ORGÂNICA}

Os argumentos expostos pela doutrina a favor do uso de uma ação direta de inconstitucionalidade de lei municipal em face de Lei Orgânica Municipal são escassos. O único autor encontrado que ainda de certa maneira consegue compreender (ainda que com ideias abstratas) a possibilidade deste tipo de controle é André Tavares. Neste sentido, vale a pena transcrever suas palavras sobre o tema:

O que resta evidente é que, se é possível proceder a um controle concreto e difuso das normas municipais em relação à Lei Orgânica, com efeito inter partes, a possibilidade de controle concentrado e abstrato nesses casos não é tese absolutamente insustentável ${ }^{21}$.

O jurista passa então a lançar, com suas palavras, ideias iniciais sobre a possibilidade deste tipo de controle. E para dar continuidade a este pensamento, essa tese será construída em cima de três pilares: a) o tratamento da Lei Orgânica Municipal como uma "constituição formal" do Município; b) a realização de uma interpretação extensiva e analógica do controle de constitucionalidade estadual, adaptando sua estrutura para a abordagem deste controle sui generis nas normas municipais; c) os Princípios da Eficiência e Economia Processual como norteadores da utilização da ADIN no âmbito municipal.

\section{LEI ORGÂNICA MUNICIPAL: STATUS DE “CONSTITUIÇÃO FORMAL E MATERIAL" DO MUNICÍPIO}

Uma das questões fundamentais da tese aqui defendida é a consideração da Lei Orgânica Municipal como uma Constituição em sentido formal.

Uma parcela majoritária da doutrina e da jurisprudência entende que a Lei Orgânica possui todos os requisitos das constituições estaduais, mas que

21 TAVARES, André Ramos. Curso de Direito Constitucional, p. 482. 
apenas deve ser considerada uma constituição em seu sentido material e não formal. Contudo, não informa a fundamentação desta afirmativa tão forte e preconceituosa para com o Município.

Talvez este pensamento de certa forma "arcaico" tenha raízes nos modelos federativos importados, que muitas vezes toma-se como padrão para a análise da federação traçada pela Constituição Federal de $1988^{22}$.

Um dos juristas que mais se debruçou sobre a questão do federalismo e a peculiaridade dos municípios no Brasil foi Paulo Bonavides. O mestre cearense assim retrata esta inovação na Carta de 88:

Poder-se-ia até dizer que a autonomia do município recebeu um reforço de juridicidade acima de tudo quanto se conhece em outros sistemas federativos tocante à mesma matéria, não podendo pois tal densidade normativa deixar de pesar bastante, toda vez que, em busca de solução para problemas concretos de inconstitucionalidade, se aplicarem os recursos hermenêuticos indispensáveis à avaliação daquela garantia, consoante o modelo e a substância das regras que fluem da Constituição.

\section{$[\ldots]$}

Todavia, no Brasil, com a explicitação feita na Carta de 1988, a autonomia municipal alcança uma dignidade federativa jamais lograda no direito positivo das Constituições antecedentes. Traz o art. 29, por sua vez, um considerável acréscimo de institucionalização, em apoio à concretude do novo modelo federativo estabelecido pelo art. 18, visto que determina seja o município regido por Lei Orgânica, votada por quórum qualificado de dois terços dos membros da Câmara Municipal - requisito formal que faz daquele estatuto um diploma dotado de grau de rigidez análogo ao que possuem as cartas constitucionais ${ }^{23}$.

Explica Bonavides que a Constituição Federal, ao determinar que a "organização político-administrativa da República Federativa do Brasil compreende a União,

22 Vid., por exemplo, o posicionamento de Uadi Bulos sobre o tema: "Sem desmerecer a grande importância dos Municípios, parece-nos que o Texto de 1988 exagerou ao incluí-lo no enlace federativo, alijando o modelo lógico-jurídico de federação e deturpando a Teoria Geral do Federalismo, que sempre previu uma federação de Estados, e não uma federação de Municípios". BULOS, Uadi Lammêgo. Curso de Direito Constitucional, p. 917. Outro argumento contrário também reside no fato de que os Municípios não possuem assento no Senado Federal, além de não manter um Poder Judiciário próprio. Cfr. MENDES, Gilmar Ferreira; GONET BRANCO, Paulo Gustavo. Curso de Direito Constitucional, p. 822.

23 BONAVIDES, Paulo. Curso de Direito Constitucional. 26. ed. São Paulo: Malheiros, 2011, p. 344-345. 
os Estados, o Distrito Federal e os Municípios, todos autônomos"24, além de estabelecer um quórum especial de aprovação da Lei Orgânica Municipal e determinar competências específicas para os municípios no art. 30, acaba por gerar uma "latitude de reconhecimento constitucional desconhecida aos textos antecedentes de nosso constitucionalismo"25.

Sendo mais específico, Alexandre de Moraes explica que a autonomia municipal, "da mesma forma que a dos Estados-membros, configura-se pela tríplice capacidade de auto-organização e normatização própria, autogoverno e autoadministração"26. E estas características todas são delineadas nas leis orgânicas municipais.

Em reconhecimento à peculiaridade do município na Federação Brasileira, o Supremo Tribunal inclusive já se manifestou no sentido de que a Constituição Estadual não pode ofender a autonomia municipal ${ }^{27}$, sendo proibido abrandar ou agravar os parâmetros limitadores do seu poder de auto-organização, estabelecendo que a Constituição Federal explicita claramente o seu caráter de "entidade infraestatal rígida", ante o seu poder de se auto-organizar por meio da Lei Orgânica Municipal28.

Desta forma, não restam dúvidas de que a Constituição Federal, além de descentralizar a federação, estabeleceu não apenas duas, mas três ordens de poder, quais sejam, a União, a ordem regional (Estados) e as ordens locais (Municípios) $^{29}$.

Observando desta forma, não há como não reconhecer que a Lei Orgânica Municipal é uma constituição do município em seu duplo sentido: tanto formal,

24 BRASIL. Constituição Federal. Art. 18.

25 BONAVIDES, Paulo. Curso de Direito Constitucional, p. 346.

26 MORAES, Alexandre de. Direito Constitucional, p. 290.

27 "A Constituição estadual não pode impor, ao Prefeito Municipal, o dever de comparecimento perante a Câmara de Vereadores, pois semelhante prescrição normativa - além de provocar estado de submissão institucional do Chefe do Executivo ao Poder Legislativo municipal (sem qualquer correspondência com o modelo positivado na Constituição da República), transgredindo, desse modo, o postulado da separação de poderes - também ofende a autonomia municipal, que se qualifica como pedra angular da organização político-jurídica da Federação brasileira". BRASIL. SUPREMO TRIBUNAL FEDERAL. ADI 687/PA, Tribunal Pleno, Rel.: Min. Celso de Mello, Julgamento: 02/02/1995.

28 BRASIL, SUPREMO TRIBUNAL FEDERAL. ADI 2112 MC/RJ, Tribunal Pleno, Relator: Min. Sepúlveda Pertence, Julgamento: 11/05/2000.

29 Neste sentido vid. CARVALHO, Kildare Gonçalves. Direito Constitucional. Teoria do Estado e da Constituição. Direito Constitucional Positivo. 15. ed. Belo Horizonte: Del Rey, 2009, p. 1027 e TAVARES, André Ramos. Curso de Direito Constitucional, p. 1.129. 
como material. Qualquer pensamento contrário remete ao tempo anterior à Constituição Federal atual, no qual a competência para elaboração das "leis de organização municipal" era dos Estados e não do Município ${ }^{30}$. Este tempo passou e o federalismo brasileiro evoluiu de maneira peculiar às características do nosso país.

Assim, frisando que a Lei Orgânica Municipal é uma lei elaborada pela Câmara de Vereadores Municipal, com um quórum de modificação especial, que regulamenta competências específicas dos Municípios que são predeterminadas pela Constituição Federal, e que este ente é considerado expressamente um membro da Federação, com auto-organização e normatização própria, autogoverno e autoadministração, não é nada fora do senso comum considerar a Lei Orgânica uma norma constitucional deste ente federado.

A doutrina e a jurisprudência a que se apega a nomenclatura de "Lei Orgânica" para estabelecer que ela é uma norma de direito comum, data venia, não enxerga (ou não quer reconhecer) a substância constitucional da Lei Orgânica e as características peculiares do Município. Em sentido oposto, maior clareza demonstra André Tavares ao afirmar que a Lei Orgânica Municipal não pode ser outra coisa, senão a "correspondente constituição do Município, que a Constituição do Brasil denominou de maneira particularizada, ressaltando sua inclinação para a organização ('orgânica') dos 'Poderes' locais" 31.

Ante o exposto, considera-se ser plenamente aceitável que a Lei Orgânica MunicipalpossaserparâmetrodeumaeventualAçãoDiretadeInconstitucionalidade de uma lei municipal, que venha a ser impetrada em um Tribunal de Justiça Estadual.

30 TAVARES, André Ramos. Curso de Direito Constitucional, p. 1.132.

31 TAVARES, André Ramos. Curso de Direito Constitucional, p. 1.133. Vid. também o posicionamento de SILVA, José Afonso da. Curso de Direito Constitucional Positivo. 36. ed. São Paulo: Malheiros: 2012, p. 644, para quem "a lei orgânica é uma espécie de constituição municipal", e RESENDE, Antônio José Calhau de. Autonomia Municipal e Lei Orgânica. Cadernos da Escola do Legislativo, Belo Horizonte, v. 10, n. 15, jan/dez 2008, p. 30, que defende "a tese de que a Lei Orgânica é a Constituição do Município, porém, sujeita aos princípios da Constituição da República e do Estado Federado, bem como aos preceitos enumerados no art. 29 da Carta Magna". 


\section{INTERPRETAÇÃO EXTENSIVA-ANALÓGICA DO CONTROLE DE CONSTITUCIONALIDADE ESTADUAL}

A jurisprudência sobre este tema parece ser uníssona em afirmar que o controle concentrado de constitucionalidade de norma municipal em face de Lei Orgânica do Município não é viável por não haver previsão expressa na Constituição. Pois bem, se não há previsão, tampouco há proibição de sua criação.

O que na verdade a Constituição trouxe foi um exemplo de ADIN que pode ser implementado no âmbito estadual, mas que esta referência é exemplificativa e não taxativa. Veja-se o que determina a Constituição Federal sobre os Tribunais de Justiça:

Art. 125. Os Estados organizarão sua Justiça, observados os princípios estabelecidos nesta Constituição.

$[\ldots]$

$\S 2^{\circ}$ - Cabe aos Estados a instituição de representação de inconstitucionalidade de leis ou atos normativos estaduais ou municipais em face da Constituição Estadual, vedada a atribuição da legitimação para agir a um único órgão.

Em nenhum momento a Constituição Federal proíbe o controle abstrato de norma municipal em face de Lei Orgânica. Veja-se que, se assim fosse o desejo do constituinte, haveria expressa proibição neste sentido, como ocorre ao final do $\S 2^{\circ}$, do art. 125 , no qual se veda a legitimidade ativa para a utilização de ADIN no âmbito estadual a um único órgão. Este sim é um exemplo claro de proibição. O que ocorre no presente caso é uma omissão.

Seguindo este raciocínio, perceba-se que esta omissão pode ser suprimida com o poder que é dado aos Estados para organizar a sua justiça e estabelecer a competência de seus tribunais:

Art. 125. Os Estados organizarão sua Justiça, observados os princípios estabelecidos nesta Constituição. 
$\S 1^{\circ}$ - A competência dos tribunais será definida na Constituição do Estado, sendo a lei de organização judiciária de iniciativa do Tribunal de Justiça.

Ademais, aos Estados também foi destinada a competência para legislar em matéria processual, conforme estipulado no art. 24, inciso XI, da Constituição:

Art. 24. Compete à União, aos Estados e ao Distrito Federal legislar concorrentemente sobre:

XI - procedimentos em matéria processual;

Desta forma, nada impede que um Estado possa estabelecer em sua constituição a possibilidade do uso de uma Ação Direta de Inconstitucionalidade de norma municipal em face da Lei Orgânica respectiva do município, a exemplo do que fez o Estado de Pernambuco na redação original (hoje revogada) de sua Constituição:

Art. 61. Compete ao Tribunal de Justiça:

I - processar e julgar originariamente:

I) a ação direta de inconstitucionalidade de lei ou ato normativo estadual ou municipal, em face desta Constituição, ou de lei ou ato normativo municipal em face da Lei Orgânica respectiva;

Note-se que a ausência de previsão expressa na Constituição Federal não tem sido empecilho (ao menos doutrinariamente) para a criação de instrumentos de controle de constitucionalidade nos Estados, utilizando-se dos raciocínios anteriormente referidos.

A Ação Declaratória de Constitucionalidade (ADC), por exemplo, que é prevista para ser impetrada perante o Supremo Tribunal, de acordo com a doutrina 
majoritária, pode ser criada também no âmbito estadual (ainda que em ausência de qualquer disposição neste sentido). Logicamente, sua criação deverá respeitar os parâmetros de seu uso na esfera federal, fundamentando-se no princípio da isonomia das pessoas jurídicas de direito público e, por conseguinte, no próprio princípio federativo ${ }^{32}$.

Uma peculiaridade em relação ao controle de normas municipais em face da Lei Orgânica é que não existe um Poder Judiciário Municipal para julgar este tipo de ação. Contudo, considera-se que isto não é um impedimento à sua criação.

Em termos práticos, acredita-se que deixar que um magistrado de primeiro grau decida esta ação não é algo salutar. Imagine-se uma cidade onde existem, por exemplo, muitas varas da fazenda pública (que talvez devesse ser a mais indicada para o julgamento) e diversos juízes emitam decisões contraditórias com efeito erga omnes sobre um mesmo dispositivo da Lei Orgânica. Certamente não haveria uma homogeneidade "constitucional" em torno da "Constituição Municipal". E este não é um dos propósitos da jurisdição constitucional.

Como o Município não é competente para legislar em matéria processual, o mais correto é que o Tribunal de Justiça do Estado é que passe a julgar uma eventual ADIN deste tipo.

Não se considera que com isto ocorra uma quebra do pacto federativo ou mesmo haja uma quebra da regra básica da jurisdição constitucional. O que se alerta é que este é um tipo de controle de constitucionalidade especial (sui generis) e que o mais indicado é que a decisão seja tomada pelo Tribunal de Justiça do Estado, e de preferência por seu órgão especial (pleno).

André Tavares alerta que não há uma uniformidade para este tipo de controle e o mais indicado é que haja o controle de constitucionalidade difuso (caso a caso) de normas municipais em face de Lei Orgânica. Contudo, afirma o autor que, caso haja uma previsão expressa na Constituição Estadual, esta sim é plenamente viável ${ }^{33}$.

32 Não são poucas as vozes nesse sentido, dentre elas: BARROSO, Luis Roberto. O Controle de Constitucionalidade no Direito Brasileiro. 6. ed. São Paulo: Saraiva, 2012, p. 61, TAVARES, André Ramos. Curso de Direito Constitucional, p. 447 e BULOS, Uadi Lammêgo. Curso de Direito Constitucional, p. 310-311.

33 TAVARES, André Ramos. Curso de Direito Constitucional, p. 482-483. 


\section{OS PRINCÍPIOS DA EFICIÊNCIA E ECONOMIA PROCESSUAL COMO NORTEADORES DA UTILIZAÇÃO DA ADIN DE NORMAS MUNICIPAIS}

Sem sombra de dúvidas, inúmeras demandas que atualmente são ingressadas no Poder Judiciário, alegando inconstitucionalidade de lei municipal em face de Lei Orgânica deste ente, poderiam ser solucionadas com uma decisão com efeito erga omnes no âmbito de uma ADIN perante o Tribunal de Justiça Estadual.

Isto não ocorre, claro, porque atualmente a doutrina e a jurisprudência entendem ser a Lei Orgânica uma lei infraconstitucional, e assim, um eventual conflito entre as duas normas seria um conflito de legalidade, e não constitucional. Dessa forma, esse controle de legalidade deveria ser analisado em cada caso concreto.

Ora, é plenamente contrário a qualquer sentido de lógica, e ao Princípio Constitucional da Eficiência e Economia Processual, um Tribunal de Justiça reconhecer a violação da Lei Orgânica de um Município por uma lei municipal e esperar que milhares de demandas repetitivas cheguem ao mesmo Tribunal, para que seja tomada a mesma decisão. São questões formais como esta que atrasam sobremaneira o Poder Judiciário Brasileiro.

Talvez a jurisprudência possa aos poucos ir evoluindo e aceitando inicialmente este tipo de controle concentrado quando a norma municipal venha a violar questões que caracterizam a Lei Orgânica Municipal como a "Constituição do Município", e que não são de repetição obrigatória, como, por exemplo, questões de interesse local, tributos municipais, servidores públicos, etc.

Esta talvez seja uma saída ponderada para uma evolução do controle de constitucionalidade abstrato e o uso da Ação Direta de Inconstitucionalidade para a representação de normas municipais em face da Lei Orgânica Municipal (Constituição do Município). 


\section{O USO DA ADIN NO DISTRITO FEDERAL: PECULIARIDADES E ESPERANÇA DE EVOLUÇÃO PARA A REGULAMENTAÇÃO NOS ESTADOS}

A disciplina jurídico-política do Distrito Federal é bastante peculiar. Caracterizado como um ente federativo, ao lado da União, dos Estados e dos Municípios, foi designado para sediar a capital do país e os poderes da República, possuindo capacidade de auto-organização, autogoverno, autoadministração e autolegislação, sendo esta última exercida com competências legislativas reservadas aos Estados e aos Municípios, contudo, não se confundindo com os dois ${ }^{34}$.

Neste compasso, o controle abstrato de constitucionalidade das leis emanadas pelo poder legislativo do Distrito Federal sempre se revestiu de peculiaridades, pois não havia nenhuma norma da Constituição Federal prevendo o julgamento pelo STF de ADIN com base em lei distrital em relação à Constituição.

Não obstante esta ausência, oSupremoTribunal Federal fixou umentendimento sui generis, de forma a permitir uma possibilidade deste controle. Em um acórdão exarado em 1992, de relatoria do ex Ministro Sepúlveda Pertence, estabeleceuse que não é cabível a ação direta de inconstitucionalidade cujo "objeto seja ato normativo editado pelo Distrito Federal, no exercício de competência que a Lei Fundamental reserva aos Municípios, qual a de disciplina e polícia do parcelamento do solo urbano" ${ }^{\prime \prime 3}$. Nesse sentido, esta jurisprudência militava a favor apenas da possibilidade do uso da ação direta de inconstitucionalidade no STF de ato aprovado pelo legislativo distrital no exercício de competência tipicamente estadual ${ }^{36}$. Posteriormente, com a Emenda Constitucional n. 45/2004, incluiu-se o Governador do Distrito Federal e a Mesa da Câmara Legislativa Distrital no rol de entes para propor a ADIN no âmbito do STF, colmatando assim a lacuna existente.

34 CUNHA JR., Dirley Da. Curso de Direito Constitucional. 4. ed. Salvador: Juspodium, 2014, p. 715716; LAUBÉ, Vitor Rolf. Distrito Federal: organização e natureza jurídica decorrentes da Constituição de 1988. Revista de Informação Legislativa, Brasília, n. 105, ano 27, jan/mar 1990, p. 54-59.

35 BRASIL. SUPREMO TRIBUNAL FEDERAL. ADIN n. 611-8 DF, Rel. Min. Sepúlveda Pertence, DJU 11/12/92.

36 MEIRELLES, Hely Lopes; WALD, Arnoldo; MENDES, Gilmar Ferreira. Mandado de Segurança e Ações Constitucionais. 33. ed. São Paulo: Malheiros, 2010, p. 410. 
Por outro lado, Gilmar Mendes ressalta uma importante inovação ocorrida no Distrito Federal: a utilização de ADIN com base em lei ou ato normativo do Distrito Federal em relação à Lei Orgânica Distrital ${ }^{37}$.

Estabelece a Lei n. 11.697/2008, que dispõe sobre a organização judiciária do Distrito Federal, que compete ao Tribunal de Justiça processar e julgar originariamente a ação direta de inconstitucionalidade de lei ou ato normativo do Distrito Federal em face de sua Lei Orgânica ${ }^{38}$, aplicando-se, no que couber, as normas sobre o processo e o julgamento da ação direta de inconstitucionalidade perante o Supremo Tribunal Federal ${ }^{39}$. Esta mesma possibilidade foi também disciplinada no Regimento Interno do Tribunal de Justiça do Distrito Federal (TJDFT) ${ }^{40}$.

Urge salientar que em nenhum momento a regulamentação exposta trata de determinar se a lei distrital objeto da ADIN perante o Tribunal de Justiça Distrital está no exercício de poder de competência reservada aos Municípios ou aos Estados. Isto tem permitido que o TJDFT julgue ADIN's de leis distritais em matéria de parcelamento do solo urbano, em violação à Lei Orgânica do Distrito Federal ${ }^{41}$, sendo que esta matéria é de competência municipal.

Ainda em relação a este último ponto, poderia se levantar a questão de que o STF, em acórdão prolatado há mais de 20 anos, considerou a Lei Orgânica do Distrito Federal equivalente, "em força, autoridade e eficácia jurídicas, a um verdadeiro estatuto constitucional, essencialmente equiparável as Constituições promulgadas pelos Estados-membros"42, e assim não haveria problema para este controle estadual: estar-se-ia atacando uma norma distrital em violação a uma norma equiparável a uma constituição estadual.

37 MENDES, Gilmar Ferreira. Jurisdição Constitucional. 6. ed. São Paulo: Saraiva, 2014, p. 221.

38 BRASIL. Lei n. 11.697/2008. Art. $8^{\circ}$, I, alínea "n".

39 BRASIL. Lei n. 11.697/2008. Art. $8^{\circ}$, § 5o.

40 A previsão no Regimento está disposta da seguinte maneira: Compete ao Conselho Especial processar e julgar originariamente a ação direta de inconstitucionalidade e a ação declaratória de constitucionalidade de lei ou de ato normativo distrital em face da Lei Orgânica do Distrito Federal e as respectivas reclamações, para garantir a autoridade de suas decisões (art. $8^{\circ}$, I, alínea "l".). A regulamentação procedimental da ADIN também foi disposta nos arts. 103 a 113. Vid. Regimento Interno do Tribunal de Justiça do Distrito Federal (Portaria GPR No 1107, de 15 de setembro de 2009).

41 Neste sentido, vid. as seguintes Ações Diretas de Inconstitucionalidades julgadas pelo TJDFT: ADIN n. 20140020187972ADI, Relator: João Timóteo de Oliveira, Julgamento: 27/01/2015; ADIN n. 20140020127637ADI, Relator: Flavio Rostirola, Julgamento: 25/11/2014.

42 BRASIL. SUPREMO TRIBUNAL FEDERAL. Medida Cautelar na ADI n. 980 / DF, Tribunal Pleno, Relator: Min. Celso de Mello, Julgamento: 03/02/1994. 
Ora, ocorre que a Lei Orgânica do Distrito Federal também possui matéria que é reservada apenas aos municípios, como questões locais de parcelamento do solo urbano ${ }^{43}$ e, assim, poder-se-ia afirmar que, em última hipótese, ela teria uma caraterística mista: uma mescla de elementos das constituições estaduais e das leis orgânicas municipais ${ }^{44}$.

Veja-se, por exemplo, que para aprovação da Lei Orgânica Distrital é necessário o mesmo quórum da Lei Orgânica Municipal ${ }^{45}$, e a Constituição Federal claramente determina que ao Distrito Federal sejam atribuídas as competências legislativas reservadas aos Estados e aos Municípios ${ }^{46}$. Além disso, não se encontra na jurisprudência do STF ou na doutrina maior discussão sobre por que o constituinte federal denominou de "lei orgânica", e não de "constituição" a lei fundamental do Distrito Federal. Ainda que a questão da nomenclatura legislativa não interfira no fundo da questão, serve de apoio à nossa tese de que de a lei orgânica do Distrito Federal pode também ser equiparada a uma lei orgânica municipal.

Neste sentido, a positivação da ADIN no Distrito Federal, tendo como referência a sua Lei Orgânica, é um exemplo a ser seguido pelos Estados. Esperase que possa haver uma evolução nesta direção, para que as normas municipais possam ter sua verificação "constitucional" concentrada em face da Lei Orgânica Municipal perante os Tribunais de Justiça Estaduais.

\section{CONSIDERAÇÕES FINAIS}

Apesar do modelo ora proposto ser desafiador e até discutível (seguramente não serão poucos a serem contrários a tal proposta), considera-se que ele é plenamente viável, desde que se tenha em mente que da mesma forma que o Município entrou na Federação Brasileira como um diferenciador (inovador) da

43 Notadamente, vid. os artigos $289, \S 6^{\circ}$ e $7^{\circ}$ e 314, b, entre outros, da Lei Orgânica do Distrito Federal. BRASIL. DISTRITO FEDERAL. LEI ORGÂNICA DO DISTRITO FEDERAL. Promulgada pela Câmara Legislativa do Distrito Federal em 08 de junho de 1993.

44 Para um estudo detalhado sobre a disposição constitucional que trata desta matéria, vid. LEONCY, Léo Ferreira. Art. 32. In: CANOTILHO, J. J. Gomes et al. (Org.). Comentários à Constituição do Brasil. São Paulo: Saraiva, 2014, p. 789-797.

45 BRASIL. Constituição Federal. Art. 32, caput.

46 BRASIL. Constituição Federal. Art. 32, § $1^{\circ}$. 
teoria clássica do federalismo, também o controle de constitucionalidade das normas municipais deve evoluir, desprendendo-se de qualquer raciocínio lógico análogo ao que se desenha no controle concentrado de constitucionalidade de normas no âmbito federal e estadual. As adaptações às inovações devem ser feitas e discutidas, e construídas por um olhar sistêmico da Constituição Federal, e não apenas de uma interpretação exegética de suas normas.

Desta forma, tendo em vista que a mesma Constituição Federal permite aos Estados estabelecerem as competências de seu Tribunal de Justiça e legislar sobre matéria processual, considera-se ser viável a implementação de uma hipótese de Ação Direta de Inconstitucionalidade de normas municipais em face da Lei Orgânica Municipal, desde que a mesma seja prevista expressamente na Constituição Estadual e seja impetrada perante o Tribunal de Justiça Estadual.

REFERÊNCIAS

BONAVIDES, Paulo. Curso de Direito Constitucional. 26. ed. São Paulo: Malheiros, 2011.

BARROSO, Luis Roberto. O Controle de Constitucionalidade no Direito Brasileiro. 6. ed. São Paulo: Saraiva, 2012.

BULOS, Uadi Lammêgo. Curso de Direito Constitucional. 6. ed. São Paulo: Saraiva, 2011.

CARVALHO, Kildare Gonçalves. Direito Constitucional. Teoria do Estado e da Constituição. Direito Constitucional Positivo. 15. ed. Belo Horizonte: Del Rey, 2009.

CUNHA JR., Dirley da. Curso de Direito Constitucional. 4. ed. Salvador: Juspodium, 2014.

JANCZESKI, Célio Armando. O Controle de Constitucionalidade de Leis Municipais. Florianópolis: Conceito Editorial, 2009.

LAUBÉ, Vitor Rolf. Distrito Federal: organização e natureza jurídica decorrentes da Constituição de 1988. Revista de Informação Legislativa, Brasília, n. 105, ano 27, jan/mar 1990, p. 47-64.

LEONCY, Léo Ferreira. Art. 32. In: CANOTILHO, J. J. Gomes et al. (Org.). Comentários à Constituição do Brasil. São Paulo: Saraiva, 2014, p. 789-797.

MEIRELLES, Hely Lopes; WALD, Arnoldo; MENDES, Gilmar Ferreira. Mandado de Segurança e Ações Constitucionais. 33. ed. São Paulo: Malheiros, 2010. 
MENDES, Gilmar Ferreira. Jurisdição Constitucional. 6. ed. São Paulo: Saraiva, 2014.

MENDES, Gilmar Ferreira; GONET BRANCO, Paulo Gustavo. Curso de Direito Constitucional. 9. ed. São Paulo: Saraiva, 2014.

MORAES, Alexandre de. Direito Constitucional. 29. ed. São Paulo: Atlas, 2013.

RESENDE, Antônio José Calhau de. Autonomia Municipal e Lei Orgânica. Cadernos da Escola do Legislativo, Belo Horizonte, v. 10, n. 15, p. 7-42. Jan/dez 2008.

SILVA, José Afonso da. Curso de Direito Constitucional Positivo. 36. ed. São Paulo: Malheiros: 2012.

STRECK, Lenio Luiz. Jurisdição Constitucional e Decisão Jurídica. 4. ed. São Paulo: Revista dos Tribunais, 2014.

TAVARES, André Ramos. Curso de Direito Constitucional. 10. ed.. São Paulo: Saraiva, 2012.

Recebido em: fev/2015

Aprovado em: jun/2015 